\title{
Effects of Nozzle Inner Surface Roughness on the Performance of Self-Resonating Cavitating Waterjets under Different Ambient Pressures
}

\author{
Deng Li11,2,3 - Yong Kang1,2,* - Xiaolong Ding1,2 - Xiaochuan Wang1,2 - Zhenlong Fang1,2 \\ 1 Wuhan University, School of Power and Mechanical Engineering, China \\ 2 Wuhan University, Hubei Key Laboratory of Waterjet Theory and New Technology, China \\ 3 University of Illinois at Urbana-Champaign, Department of Mechanical Science and Engineering, United States
}

The self-resonating cavitating waterjet (SRCW) has been widely used for many practical and industrial applications since the first recognition of its strong cavitation ability. To further improve the performance of SRCW under ambient pressures, the effects of nozzle inner surface roughness were experimentally studied by impinging the jets on pure aluminium specimens (1070A) at various standoff distances. The typical macroscopic appearances and mass losses of the eroded specimens were used to evaluate the performances of the jets issuing from six organ-pipe nozzles of different inner surface roughness values $(0.8 \mu \mathrm{m}, 1.6 \mu \mathrm{m}, 3.2 \mu \mathrm{m}, 6.3 \mu \mathrm{m}, 12.5 \mu \mathrm{m}$, and $25 \mu \mathrm{m})$. The results show that nozzle inner surface roughness significantly influences the optimum standoff distance and the cavitation intensity, which greatly depends on the ambient pressure. Moreover, it is found that there is always an optimum surface roughness that can remarkably enhance the cavitation erosion capability under each ambient pressure. Specifically, at ambient pressures of $2 \mathrm{MPa}$ and $4 \mathrm{MPa}$, the surface roughness of $6.3 \mu \mathrm{m}$ causes the strongest cavitation intensity at standoff distances of $42 \mathrm{~mm}$ and $50 \mathrm{~mm}$, respectively. While at ambient pressures of $6 \mathrm{MPa}, 8$ $\mathrm{MPa}$, and $10 \mathrm{MPa}$, the surface roughness of $12.5 \mu \mathrm{m}$ is the one that maximally enhances the intensity at standoff distances of $45 \mathrm{~mm}, 40$ $\mathrm{mm}$, and $35 \mathrm{~mm}$, respectively. Furthermore, the enhanced cavitation intensity is found to improve the impingement power of the high-speed waterjet as well. The present study also helps to provide a guideline for determining the finishing accuracy of inner surface required in the fabrication of organ-pipe nozzles.

Keywords: self-resonating cavitating waterjet, surface roughness, cavitation erosion, ambient pressure, organ-pipe nozzle

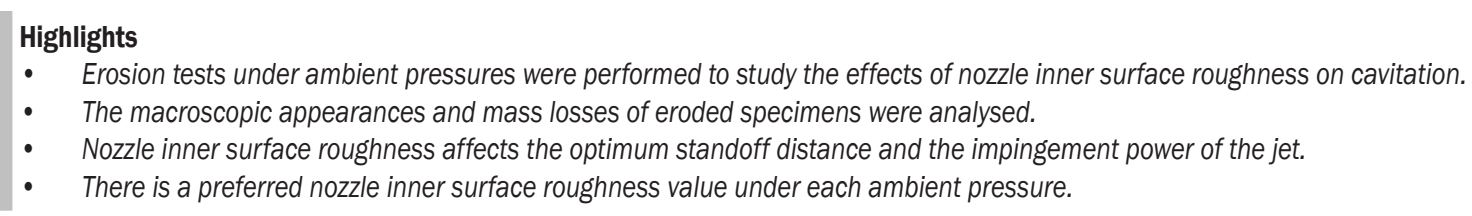

\section{INTRODUCTION}

Cavitation is the formation of vapor bubbles in a liquid and happens when the local pressure is lower than the vapor pressure of the liquid [1]. It can be easily generated with high-speed waterjets. The collapse of cavitation bubbles near a solid boundary can cause very high amplitude and small duration impulsive loads and emits a large amplitude pressure wave, which subsequently leads to serious local damage [2]. Based on this feature, cavitating waterjet, which can be produced by creating a large number of bubbles in the periphery of the jet, has been proposed and is now being used in a wide spectrum of applications, such as cavitation peening, removal coating [3], cleaning [4], cutting [5], deep-hole drilling [6], and killing bacteria [7].

To enhance the cavitation intensity of the cavitating waterjet for better utilization, a considerable number of investigations related to the mechanism of cavitation and methods for promoting it have been conducted. In more specific terms, Biluš et al. [8] performed an experimental analysis of the structure dynamics of cavitation cloud and corresponding pressure fluctuations. They concluded that there is a strong interaction between pressure and cavitation cloud with two dominant frequency bands. Soyama [9] experimentally studied the effect of various types of nozzle geometries on the aggressive intensity of cavitation erosion. Based on a control volume concept, Zhou et al. [10] developed a novel lumped parameter model of cavitating orifice flow by using the computational fluid dynamic method. Furthermore, several self-resonating cavitating nozzles, named "Pulser", "Pulser-Fed", "Laid-back Pulser", and "Organ-pipe", have been proposed and investigated by Johnson et al. [11]. Waterjets issuing from these nozzles have large-scale coherent structures and vortex rings in the shear layer, which can dramatically increase the cavitation intensity.

A schematic diagram of the generation and working principles of SRCW is shown in Fig. 1 with the use of an organ-pipe nozzle, which is one of the 
most promising nozzles in applications due to its simple structure and strong cavitation ability [12].

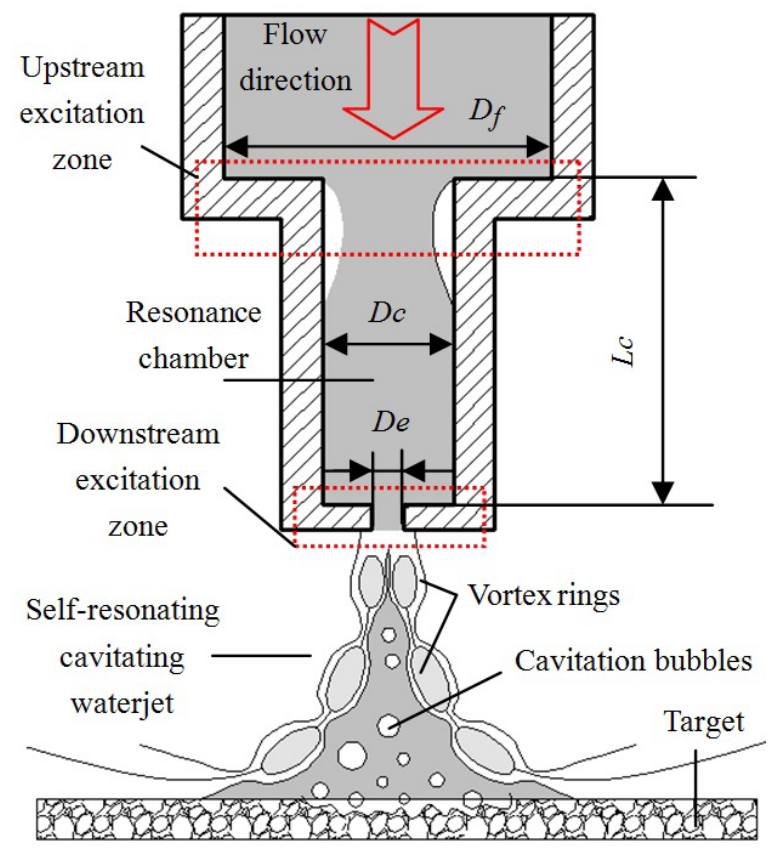

Fig. 1. Schematic diagram of the operating principles of an SRCW issuing from an organ-pipe nozzle

As is shown in the figure, an organ-pipe nozzle consists of an upstream area contraction $\left(D_{f} / D_{c}\right)$, a downstream area contraction $\left(D_{c} / D_{e}\right)$, and a resonant chamber with a length of $L_{c}$ and a diameter of $D_{c}$. When a high-speed flow is passing through the nozzle, pressure waves will be formed at the downstream area contraction because of the sudden changes of the flow velocity. These waves propagate upwards and then are reflected at the upstream contraction due to the change of impedance. At this time, the upstream and downstream contractions are excitation zones, which are the geometrical foundation for producing SRCWs. Then, the incident waves are superimposed on the reflected waves, and an acoustic resonance will finally be formed if the length of the chamber is designed to shape a standing wave [11] to [14]. The peak resonance can be achieved by matching the fundamental frequency of the organ-pipe nozzle with the critical jet structuring frequency. Moreover, the exact frequency of peak resonance depends on the end impedances; for instance, if both $\left(D_{f} / D_{c}\right)^{2}$ and $\left(D_{c} / D_{e}\right)^{2}$ are large, the first model natural frequency of the chamber will occur when the wavelength in the fluid is approximately four times the chamber length $L_{c}$ [13].
When an SRCW is produced, the energy content of the jet can be dramatically amplified, because the shear layer of the jet can be organized into large ring vortices emitted from the nozzle at a discrete frequency and could cavitate to form toroidal bubbles [14]. The formation, growth, and collapse of these bubbles could cause very high-pressure fluctuations that can be further enhanced by the self-resonance to several orders of magnitude higher, resulting in the greatly improved cavitation erosion capability of the jet [15]. These features make SRCWs especially suitable for deep-hole drilling, where high ambient pressures can prevent the formation of cavitation bubbles in conventional cavitating jets because of the low incipient cavitation numbers [16]. Furthermore, it has already been proven that SRCW has stronger cavitation erosion ability at relatively greater ambient pressures. To be more specific, Johnson et al. [17] experimentally claimed that the incipient cavitation numbers for SRCWs were generally two to six times higher than conventional cavitating waterjets under the same ambient pressure. Results of field trials conducted by Li et al. [18] revealed that the drilling rate in deep oil wells of high ambient pressures could be considerably improved from $10.1 \%$ to $31.5 \%$ with the use of SRCWs.

Even though SRCW has many advantages over conventional cavitating jets under ambient pressure conditions, to the best of our knowledge, few investigations have been performed to understand the influence of nozzle inner surface roughness on the cavitation erosion capabilities of the jets. However, nozzle inner surface roughness is expected to affect the cavitation characteristics significantly. Based on a numerical investigation on the effects of wall roughness on cavitating flow, Echouchene et al. [19] concluded that wall roughness leads to higher shear stresses in the liquid and produces additional disturbance of the velocity and pressure. In addition, Chang et al. [20] experimentally found that the nozzle inlet surface roughness can affect the occurrence of cavitation much more than it affects hydraulic flip. Most importantly, in our most recent studies [21] and [22], it has been shown that the nozzle inner surface roughness can have dramatic effects on the axial pressure oscillations as well as the cavitation erosion intensity and efficiency of SRCW.

As the strong cavitation ability under ambient pressures is one of the greatest advantages of SRCW, the purpose of this study is to further improve the aggressive intensity of cavitation erosion by investigating the effects of nozzle inner surface roughness. 


\section{RELATIONS BETWEEN SURFACE ROUGHNESS, TURBULENT FLOW, AND CAVITATION}

Turbulent flow occurs when the ratio of inertial force to viscous force exceeds a critical value, and its intensity can be measured by the Reynolds number $(R e)$. In a turbulent flow, the violent and unsteady motions of the fluid particles make the flow highly irregular, which produces large pressure fluctuations in the fluid. When the local pressure drops below the vapor pressure, cavitation occurs and then disordered, and unstable eddies are formed in the fluid. The formed vortices have a tendency of pairing into vortex rings of many different length scales, which greatly impacts the flow behaviours, including energy dissipation and pressure pulsations [23].

Fig. 2 illustrates the structure of a fully turbulent viscous flow passing through a circular pipe of the rough inner surface. As shown in the figure, the flow structure can be divided into viscous sublayer region and turbulent core region. Though the thickness of the viscous sublayer is rather small (about $10 \%$ of the boundary layer thickness), the viscous shear force in the layer plays a significant role on the turbulence properties, such as the convective heat transfer, momentum and mass exchange, and energy diffusion [24]. If the viscous sublayer is affected, cavitation, which is closely related to the turbulent characteristics, will be influenced as a result.

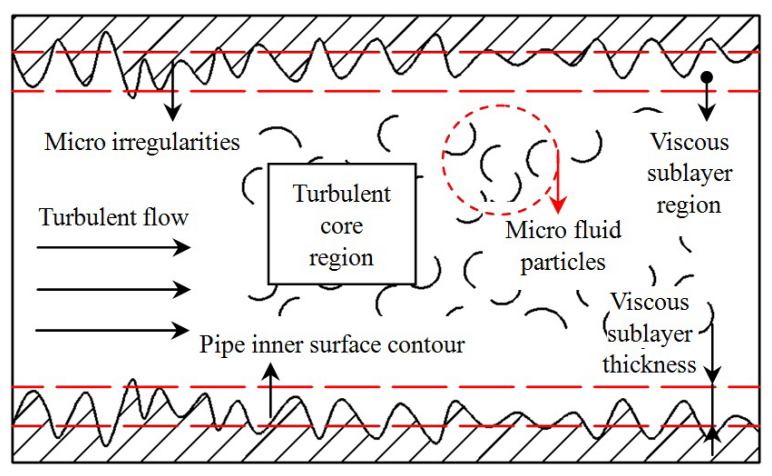

Fig. 2. Schematic of flow structure of turbulent flow over rough surface

Because of the practical limitations on surface machining, the inner surface of the nozzle is not ideally smooth but has enormous amounts of microirregularities called roughness elements. If the magnitude of roughness element height is similar to the viscous sublayer thickness, violent interactions between the roughness elements and the viscous sublayer will happen and thus significantly influence the turbulent flow. Based on the relations between turbulence and cavitation mentioned above, it can be deduced that once the turbulent flow is affected, the cavitation process will be influenced as well. This assumption is in accordance with one of the studies on the influence of surface roughness on turbulent flow, carried out by Nikuradse [25]. He demonstrated that the velocity distribution of the turbulent flow was dramatically dependent on the relative roughness. By means of experimental investigation, Li et al. [26] found that when the roughness height is more than five times the viscous sublayer thickness, the flow friction, which can cause large pressure drops in the fluid, begins to increase sharply. In contrast, when a highspeed liquid is flowing over the roughness elements, fluid separation tends to occur, which will promote the generation of cavities and thus the cavitation erosion intensity.

A preliminary calculation (detail is shown in Section 3.2) has shown that the most commonly used surface roughness values $\left(0.8 \times 10^{-6} \mathrm{~m} \sim 25 \times 10^{-6} \mathrm{~m}\right)$ are of the same order of magnitude with the thickness of viscous sublayer at high Reynolds numbers. So, combined with the previous related literature [19] to [22], it could be expected that nozzle inner surface roughness should put some effects on the cavitation erosion ability of SRCW.

\section{EXPERIMENTAL SETUP AND PROCEDURES}

\subsection{Experiment Apparatus and Procedures}

A schematic diagram of the experimental setup for the cavitation erosion test under several ambient pressures is shown in Fig. 3. Pressured tap water was supplied from a plunger pump whose working pressure can be continuously regulated through the control table from $0 \mathrm{MPa}$ to $60 \mathrm{MPa}$ with a maximum flow rate of $120 \mathrm{l} / \mathrm{min}$. Two bladder accumulators were applied to minimize the influence of pressure fluctuations of the pump on the experimental results. Specifically, one accumulator was installed near the pump, and the other one was positioned close to the nozzle being tested, as shown in Fig. 3. To remove the effects of pressure loss in the pipeline under different operating conditions, a pressure transducer (Model: BD DMP331P), which had been calibrated by the manufacturer, was installed immediately before the nozzle to make sure that the inlet pressure $\left(P_{\mathrm{i}}\right)$ of each test was consistent with the designed value of $25 \mathrm{MPa}$. The range and accuracy of the pressure transducer were $1 \mathrm{MPa}$ to $40 \mathrm{MPa}$ and $\pm 0.05 \% \mathrm{FS}$, respectively. And in each test, the shutter would not be removed until the value obtained by this transducer remained stable. 


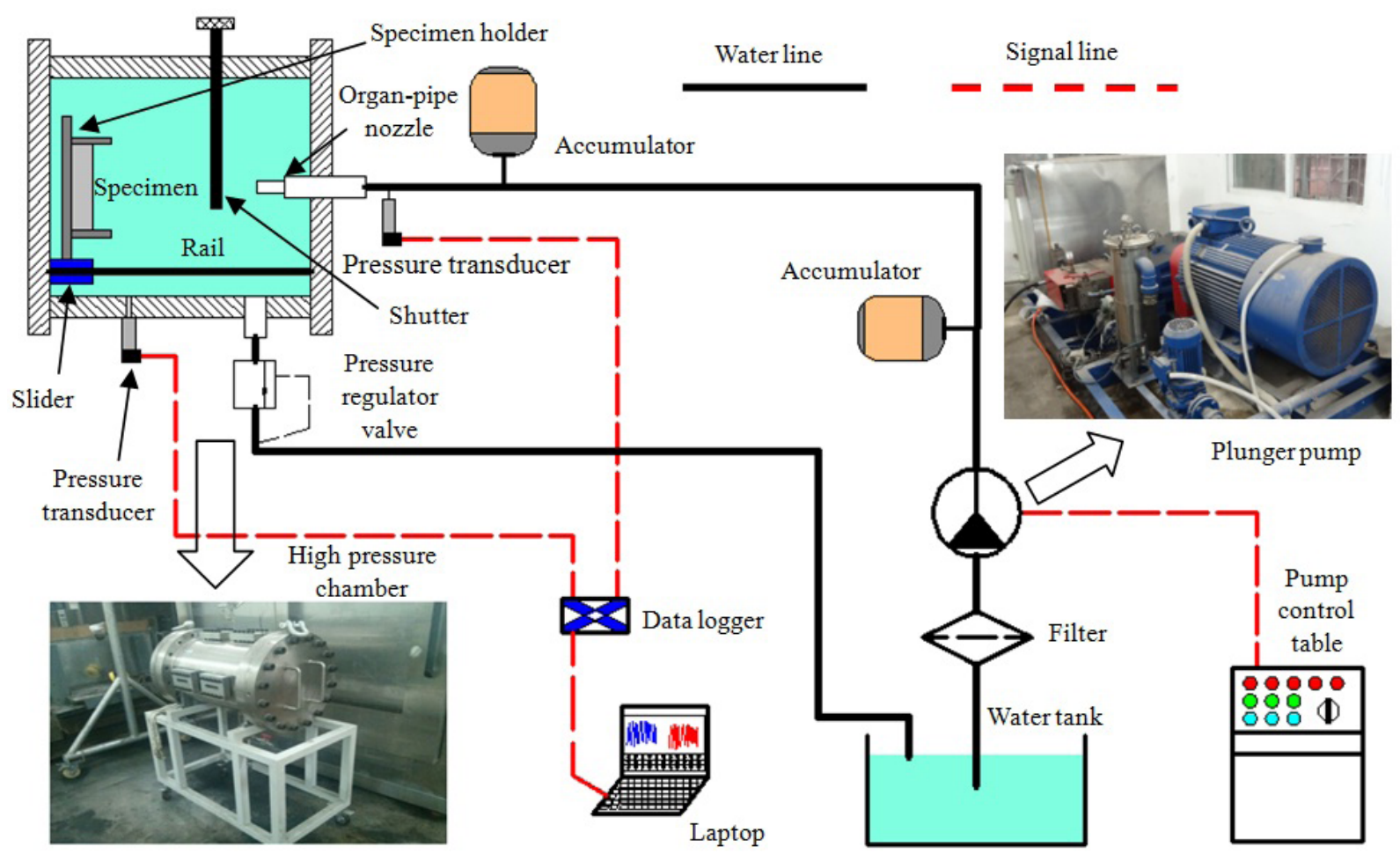

Fig. 3. Schematic of experimental setup for erosion tests

The tests were conducted in a high-pressure chamber made of stainless steel. The maximum design pressure of the chamber was $10 \mathrm{MPa}$, and the achievable standoff distance was $300 \mathrm{~mm}$ with a regulation precision of $0.5 \mathrm{~mm}$. The chamber pressure (which is also the ambient pressure $P_{\mathrm{a}}$ ) was regulated and controlled by an electromagnetic relief valve, as shown in the figure. Standoff distance, $S$, was defined as the distance from nozzle exit to the impingement surface of the specimen. Preliminary tests had been performed to determine a proper range of the testing standoff distance, which was from $10 \mathrm{~mm}$ to 100 $\mathrm{mm}$ with an interval of $10 \mathrm{~mm}$. During the process of each test, the chamber pressure was monitored by another pressure transducer of the same model. The erosion time for each test was 180 seconds, which was guaranteed by removing the shutter between the nozzle and the specimen in the chamber.

The mass of each specimen was measured before and after each erosion test, and mass loss, $\Delta m$, was defined as the difference between the two values. The specimen was measured on an electronic balance (Model: Sartorius BSA224S-CW) with a resolution of $0.1 \mathrm{mg}$ and linearity of $0.2 \mathrm{mg}$.

\subsection{Nozzles and Specimens}

In this experiment, all the organ-pipe nozzles had the same geometry with $D_{f}=13 \mathrm{~mm}, D_{c}=5 \mathrm{~mm}, D_{e}=2$ $\mathrm{mm}$, and $L_{c}=18 \mathrm{~mm}$, which were obtained based on the design principles of organ-pipe nozzle proposed by Chahine [14]. The inner surface roughness values of the six nozzles (shown in Fig. 4) were $0.8 \mu \mathrm{m}, 1.6$ $\mu \mathrm{m}, 3.2 \mu \mathrm{m}, 6.3 \mu \mathrm{m}, 12.5 \mu \mathrm{m}$, and $25 \mu \mathrm{m}$, respectively, which were achieved by changing the machining process on a high-precision digital controlled lathe [22]. These roughness values are the most commonly used in machining nozzles of similar size. Before the tests, the inner surface roughness of each nozzle was measured on a roughness measuring instrument (Model: Hommel-Etamic T800 RC) with a resolution of $1 \mathrm{~nm}$ to ensure the precise accuracy of the roughness values. The manufacturer was Metrology, and the measuring range was $0.1 \mu \mathrm{m}$ to $120 \mathrm{~mm}$.

Considering that pure aluminium is commonly used in cavitation erosion tests [22], [28], and [29], the same material was used as a specimen here. The chemical composition and physical properties of the specimen are listed in Tables 1 and 2, respectively. It should be noted that the surface of each specimen exposed to the impingement of the jets had been 
Table 1. Chemical composition of specimen (mass\%)

\begin{tabular}{cccccccccc}
\hline Material & Chinese standard & $\mathrm{Al}$ & $\mathrm{Si}$ & $\mathrm{Cu}$ & $\mathrm{Mg}$ & $\mathrm{Zn}$ & $\mathrm{Mn}$ & $\mathrm{Ti}$ & $\mathrm{Fe}$ \\
\hline Pure aluminium & $1070 \mathrm{~A}$ & 99.70 & $\leq 0.20$ & $\leq 0.03$ & $\leq 0.03$ & $\leq 0.07$ & $\leq 0.03$ & $\leq 0.03$ & $0.000 \sim 0.250$ \\
\hline
\end{tabular}

Table 2. Physical properties of specimen

\begin{tabular}{ccccccc}
\hline Material & Chinese standard & $\begin{array}{c}\text { Density } \\
\rho \times 10^{3}\left[\mathrm{~kg} / \mathrm{m}^{3}\right]\end{array}$ & $\begin{array}{c}\text { Elasticity modulus } \\
E \times 10^{9}[\mathrm{~Pa}]\end{array}$ & $\begin{array}{c}\text { Tensile strength } \\
\sigma_{\mathrm{b}} \times 10^{6}[\mathrm{~Pa}]\end{array}$ & $\begin{array}{c}\text { Offset yield strength } \\
\sigma_{0.2} \times 10^{6}[\mathrm{~Pa}]\end{array}$ & $\begin{array}{c}\text { Vickers hardness } \\
H v \times 10^{9}[\mathrm{~Pa}]\end{array}$ \\
\hline Pure aluminium & $1070 \mathrm{~A}$ & 2.71 & 71 & 55 & 15 & 38 \\
\hline
\end{tabular}

polished and measured on the mentioned roughness measuring instrument to ensure the uniformity of specimens.

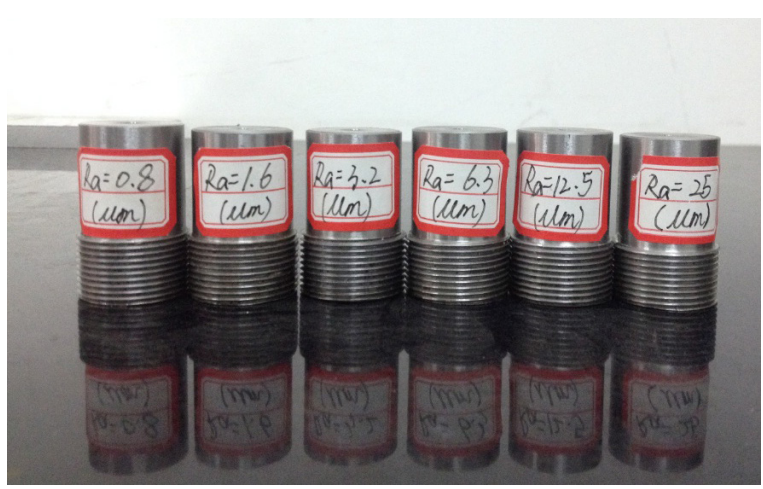

Fig. 4. The testing organ-pipe nozzles

\section{RESULTS AND DISCUSSION}

Based on the previous related theoretical and experimental efforts [2], [22], and [28], the effects of nozzle inner surface roughness on the cavitating erosion intensity of SRCW were evaluated from the aspects of both the macroscopic appearances and the mass losses of the eroded specimens.

\subsection{Macroscopic Appearances of the Eroded Specimens}

Fig. 5 shows the macroscopic appearances of the eroded specimens at an ambient pressure of $4 \mathrm{MPa}$ and a standoff distance of $40 \mathrm{~mm}$. These photographs are chosen and displayed because the appearances reveal the most obvious differences at these operating conditions. From the size of the pit and the distribution density of the dots as well as the size of the eroded area, one can have a visualized and preliminary understanding of the effects of nozzle inner surface roughness on the cavitation erosion performance of SRCW.

As can be observed in the figure, all the eroded specimens have the typical appearance of cavitation erosion with a pit at the centre and a ring shape as the main erosion region composed of numerous small dots [28] to [30]. The pit is caused by the high-speed waterjet impingement of droplets, and the ring shape is created by a cavitation cloud. More specifically, when a cavitation bubble collapses to a boundary, microjets are formed during the process and subsequently a shock wave is generated at the moment of rebounding, resulting in the damage of materials most possibly through fatigue erosion [2]. It is clear that nozzle inner surface roughness significantly affects the cavitation ability. In more specific terms, the sizes of the pit in the centre are nearly the same with a diameter of about $4 \mathrm{~mm}$ for surface roughness values of $0.8 \mu \mathrm{m}, 1.6$ $\mu \mathrm{m}$, and $3.2 \mu \mathrm{m}$. Moreover, the distribution of small dots composing the ring shape is somewhat scattered, and the general size is relatively small, meaning the cavitation abilities of these three nozzles are similar. Since the surfaces of these three nozzles are rather smooth, it should be reasonable to conjecture that this is because the mean height of the roughness elements is rather small compared with the viscous sublayer thickness under this condition. This is hydraulically smooth turbulent flow [25]. Therefore, the roughness elements can hardly protrude and interact with the viscous sublayer, and the turbulent behaviours of the high-speed flow cannot be affected nor can the cavitation ability.

From Fig. 5, it can be observed that the macroscopic appearance of the specimen eroded by the jets from the nozzle of the inner surface roughness of $6.3 \mu \mathrm{m}$ is the most apparent, with respect to both the pit at the centre and the dots composing the ring shape. The pit has a diameter of about $8 \mathrm{~mm}$, which is twice that of the pits on the specimens eroded by the jets from the nozzles of surface roughness values below $3.2 \mu \mathrm{m}$. In addition, the general sizes of the dots are larger, and the distributions are more concentrated. This indicates that both the high-speed waterjet impingement and the cavitation intensity are dramatically enhanced. Moreover, the improved 


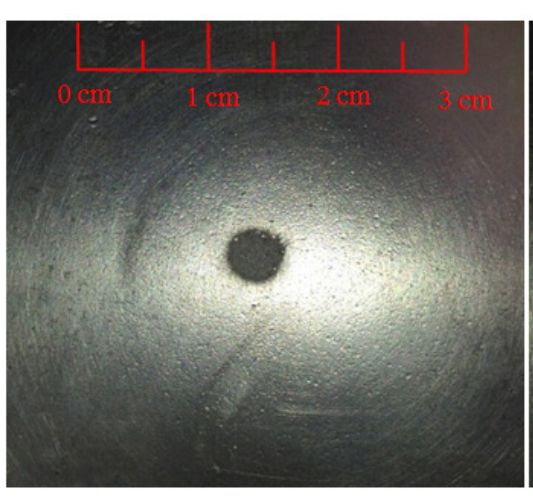

$\mathrm{Ra}=0.8 \mu \mathrm{m}$



$\mathrm{Ra}=6.3 \mu \mathrm{m}$



$\mathrm{Ra}=1.6 \mu \mathrm{m}$

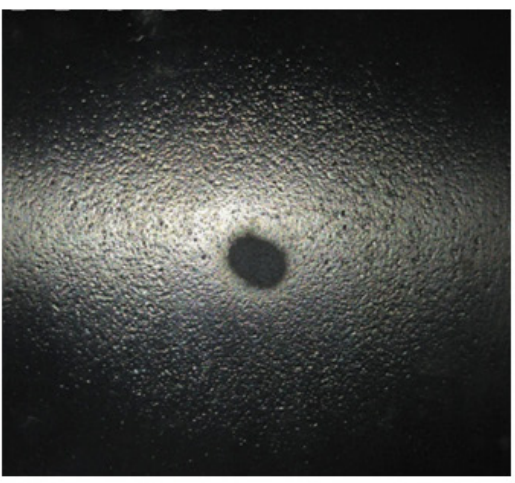

$\mathrm{Ra}=12.5 \mu \mathrm{m}$

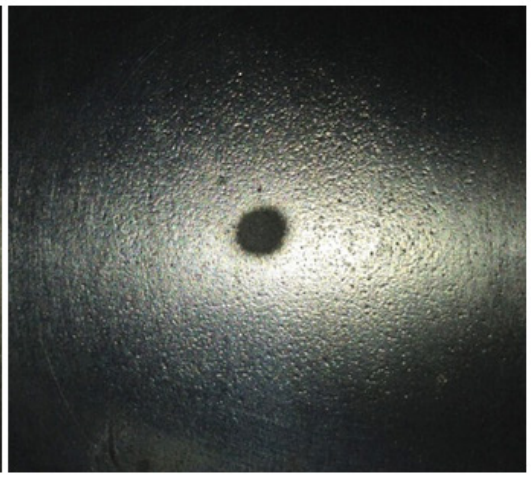

$\mathrm{Ra}=3.2 \mu \mathrm{m}$

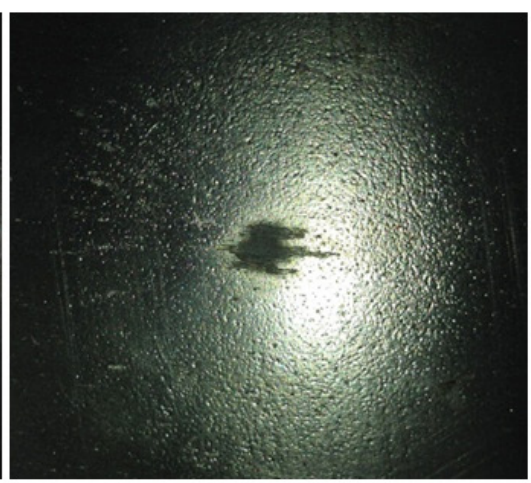

$\mathrm{Ra}=25 \mu \mathrm{m}$

Fig. 5. Photographs of the eroded specimens at $\mathrm{Pa}=4 \mathrm{MPa}, \mathrm{S}=40 \mathrm{~mm}$, and $\sigma=0.190$

cavitation intensity is most probably caused by the increased inner surface roughness, as it is the only variable between each erosion test. It can be deduced that the improved impingement ability of the highspeed waterjet is most likely to be induced by the enhanced cavitation intensity. To be more specific, the promoted cavitation produces more bubbles around the jet periphery, leading to a great reduction of the friction and interaction between the high-speed jet and the surrounding fluid [29]. As a result, the high-speed water jet contains more energy, which subsequently leads to a bigger size of the pit at the centre.

With the surface roughness value increased to $12.5 \mu \mathrm{m}$, the sizes of the pit and the small dot become smaller again, meaning a reduction of both the impingement of high-speed waterjet and the cavitation intensity. This phenomenon is more evident when the nozzle inner surface roughness is increased to 25 $\mu \mathrm{m}$. Under this condition, the pit is no longer a circle, indicating the jet beam is dispersed. The phenomenon suggests that surface roughness elements already violently interact with the high-speed flow through the viscous sublayer and put a disadvantageous effect on the cavitation erosion performance of SRCW. In contrast, it can be concluded that, under the current condition, surface roughness value of $6.3 \mu \mathrm{m}$ is a critical value for the nozzle to achieve the strongest cavitation intensity. Below this value, surface roughness has little effect on the cavitation erosion behaviours, while above the value surface roughness will reduce the cavitation intensity.

\subsection{Cavitation Erosion Intensity}

Fig. 6 shows the mass loss of eroded specimen as a function of standoff distance with respect to various ambient pressures and values of nozzle inner surface roughness.

Each curve experiences a peak at a distance where the maximum mass loss occurs. This distance is called the optimum standoff distance. This observation suggests that the existence of an optimum standoff distance is a common feature of SRCW, regardless of the nozzle inner surface roughness. The main reason 

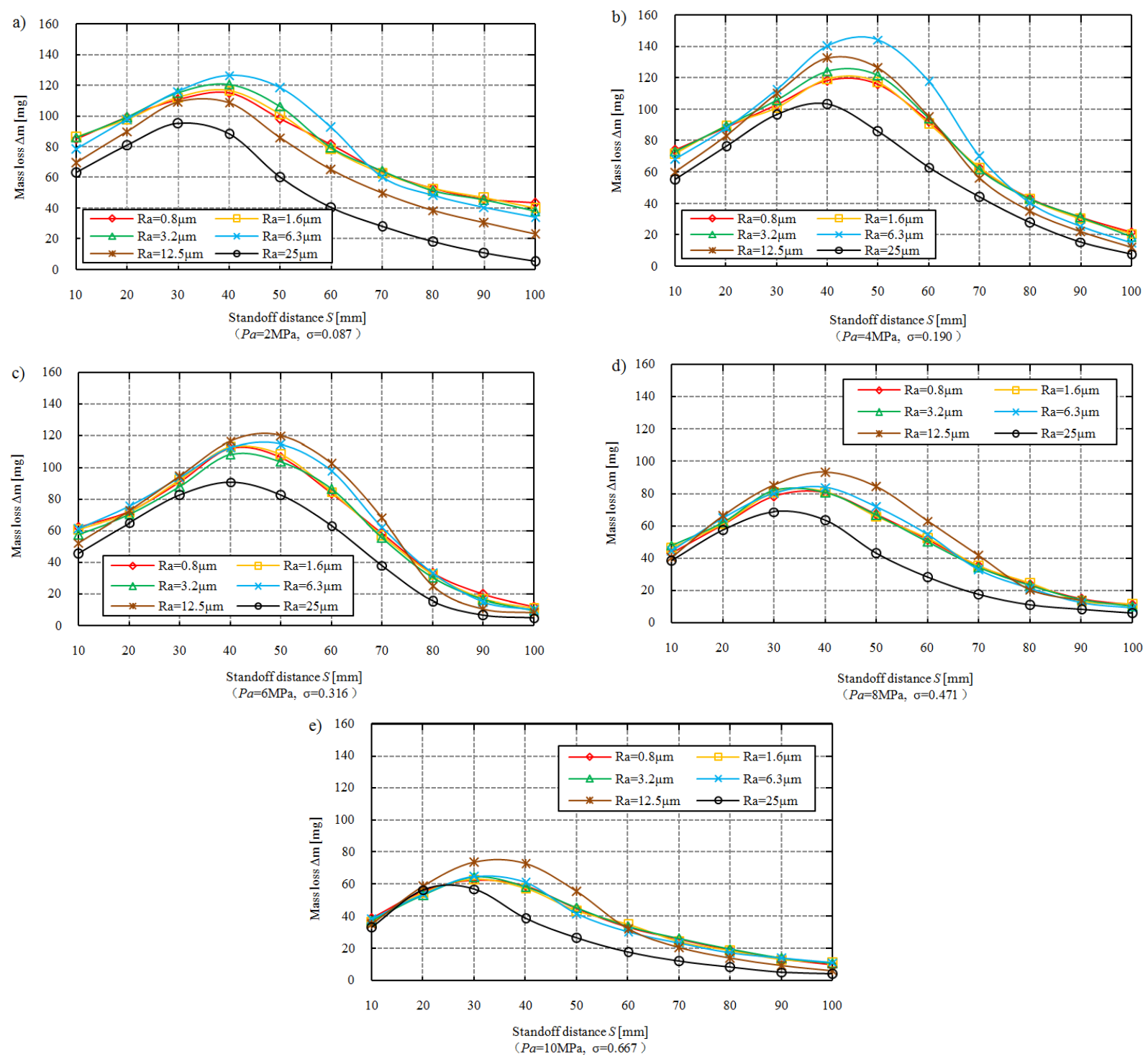

Fig. 6. Mass loss as a function standoff distance at different ambient pressures;

a) $\mathrm{Pa}=2 \mathrm{MPa}$, b) $\mathrm{Pa}=4 \mathrm{MPa}, \mathrm{c}) \mathrm{Pa}=6 \mathrm{MPa}$, d) $\mathrm{Pa}=8 \mathrm{MPa}$, e) $\mathrm{Pa}=10 \mathrm{MPa}$

for the occurrence of optimum standoff distance is that bubbles generated in the boundary or shear layer need a certain time to grow into sizes at which the collapse of cavitation clouds could produce destructive power for the specimens [2]. Therefore, analysing the optimum standoff distance is an important way to evaluate the effects of nozzle inner surface roughness on cavitation erosion. Moreover, the figure makes it possible to determine a proper range of standoff distances where strong cavitating capabilities can be achieved under different operating conditions.

It is of great interest to note that even the nozzles have different values of surface roughness; the optimum standoff distance for each nozzle experiences the same tendency. More specifically, the optimum standoff distance first increases and then decreases with the increase of ambient pressure. This is in rough agreement with the experimental results obtained by Li et al. [18] and [31] who concluded that the optimum standoff distance should keep increasing with the increase of ambient pressure. The statement was that the increasing ambient pressure suppresses the bubbles. As a consequence, additional time was needed for the bubbles to grow, leading to an increase of the optimum standoff distance. Actually, this can also be used to explain the increased optimum 
standoff distance at ambient pressures below $6 \mathrm{MPa}$. Since a certain degree of ambient pressure has the ability to keep the bubbles from bursting, more cavitation bubbles will exist in the shear layer under this condition. Another reason for the increasing optimum standoff distance should be the largely reduced friction between the jet and the surrounding fluid, caused by the enormous cavitation bubbles generated in the free shear layer. However, when the ambient pressure exceeds $6 \mathrm{MPa}$, the convective heat transfer and momentum and mass exchange between the jet and the ambient liquid become so violent that the energy of the jet dissipates rapidly with increasing standoff distance [32], leading to the decrease of the optimum standoff distance. In contrast, at high ambient pressures, pressure fluctuations around the jet are largely attenuated, causing a decrease in the number of cavitation bubbles. As a result, cavitating erosion intensity is dramatically weakened, which is reflected as a reduction of the optimum standoff distance [11].

It is a fact that an optimum standoff distance under all ambient pressures exists regardless of nozzle surface roughness. However, the values of the optimum standoff distance are different. For example, at ambient pressure of $2 \mathrm{MPa}$, the optimum standoff distance for the nozzle with a roughness value of 6.3 $\mu \mathrm{m}$ is around $45 \mathrm{~mm}$, while for roughness values of $12.5 \mu \mathrm{m}$ and $25 \mu \mathrm{m}$, it is about $35 \mathrm{~mm}$. Furthermore, at ambient pressure of $2 \mathrm{MPa}$ and $4 \mathrm{MPa}$, the optimum standoff distance of a nozzle with roughness value of $12.5 \mu \mathrm{m}$ is always the largest. Furthermore, at ambient pressure of $6 \mathrm{MPa}, 8 \mathrm{MPa}$, and $10 \mathrm{MPa}$, the optimum standoff distance of a nozzle with a roughness value of $25 \mu \mathrm{m}$ is the largest.

In contrast, if the maximum mass loss is considered, it can be found that a roughness value of $6.3 \mu \mathrm{m}$ is the best one at ambient pressures of 2 $\mathrm{MPa}$ and $4 \mathrm{MPa}$, while roughness value of $12.5 \mu \mathrm{m}$ takes its place to be the best one at pump pressures of $6 \mathrm{MPa}, 8 \mathrm{MPa}$, and $10 \mathrm{MPa}$. Specifically, proper surface roughness can promote the generation of cavitation bubbles, which is in satisfying agreement with the results obtained by Numachi et al. [33], who experimentally demonstrated that surface roughness could advance cavitation inception. Similar evidence can also be obtained from the research performed by Chang et al. [20].

Despite the influence of surface roughness on the value of optimum standoff distance, it is observed that nozzle inner surface roughness also significantly affects the magnitudes of the mass losses of the specimens.
As the figure illustrates that curves of roughness values of $0.8 \mu \mathrm{m}$ and $1.6 \mu \mathrm{m}$ are overlapped all the time, which means surface roughness below $1.6 \mu \mathrm{m}$ have little effect on the cavitation erosion intensity. This is consistent with the assumption that the chamber plays a dominating role when the surface is relatively smooth. It is interesting to note that the maximum mass loss caused by the roughness value of $3.2 \mu \mathrm{m}$ is a little larger than that caused by roughness values of $0.8 \mu \mathrm{m}$ and $1.6 \mu \mathrm{m}$ at lower ambient pressures (Fig. $6 \mathrm{a}$ and $\mathrm{b})$. However, the difference between these curves diminishes gradually with increasing ambient pressure. After the ambient pressure has exceeded $6 \mathrm{MPa}$, the difference disappears (Fig. 6c and d). In addition, a surface roughness value of $25 \mu \mathrm{m}$ should be avoided in the fabrication of organ-pipe nozzles because it leads to the weakest erosion intensity.

In order to provide a further discussion on the effects of nozzle inner surface roughness, the viscous sublayer thickness under each ambient pressure has been calculated and is shown in Table 3. It should be emphasized that only viscous sublayer thicknesses at nozzle chamber and exit were calculated because the velocity at nozzle inlet $\left(U_{i}\right)$ is nearly $2.37 \%$ the velocity at nozzle exit $\left(U_{e}\right)$. The calculation process is shown below.

The Bernoulli equation is [24]:

$$
\frac{P_{i}}{\rho g}+\frac{U_{i}^{2}}{2 g}=\frac{P_{a}}{\rho g}+\frac{U_{e}^{2}}{2 g}+h_{f}+h_{j},
$$

where $\rho$ is the liquid density, $g$ is the acceleration of gravity, $h_{f}$ is the frictional head loss, $h_{j}$ is the local head loss.

$$
\begin{gathered}
h_{f}=\lambda \frac{l}{d} \frac{u^{2}}{2 g}, \\
h_{j}=k \frac{u^{2}}{2 g},
\end{gathered}
$$

where $\lambda$ is the friction coefficient, $l$ is the length of the flow channel (here it is the nozzle length), $d$ is channel diameter, $u$ is flow velocity, and $k$ is the local resistance coefficient. Under the sudden contraction condition, $k$ can be expressed as:

$$
k=\frac{1}{2}\left(1-\left(\frac{A_{2}}{A_{1}}\right)^{2}\right)^{2},
$$

where $A_{1}$ and $A_{2}$ are the cross-section areas at the contraction.

In Eq. (2), $\lambda, l$, and $u$ are rather small. So, it can be neglected during the calculation. When compared with $U_{e}, U_{i}$ can also be neglected. 
Table. 3. Thickness of viscous sublayer under different conditions (in $[\mu m$,$] )$

\begin{tabular}{|c|c|c|c|c|c|c|c|c|c|c|}
\hline \multirow{3}{*}{$\mathrm{Ra}[\mu \mathrm{m}]$} & \multicolumn{10}{|c|}{$P_{a}[\mathrm{MPa}]$} \\
\hline & \multicolumn{2}{|c|}{2} & \multicolumn{2}{|c|}{4} & \multicolumn{2}{|c|}{6} & \multicolumn{2}{|c|}{8} & \multicolumn{2}{|c|}{10} \\
\hline & Chamber & Exit & Chamber & Exit & Chamber & Exit & Chamber & Exit & Chamber & Exit \\
\hline 0.8 & 9.011 & 0.0965 & 9.630 & 0.101 & 10.015 & 0.106 & 10.353 & 0.112 & 11.210 & 0.120 \\
\hline 1.6 & 9.011 & 0.104 & 9.630 & 0.109 & 10.015 & 0.115 & 10.353 & 0.121 & 11.210 & 0.129 \\
\hline 3.2 & 0.627 & 0.113 & 0.675 & 0.118 & 0.702 & 0.125 & 10.353 & 0.134 & 11.210 & 0.140 \\
\hline 6.3 & 0.679 & 1.170 & 0.732 & 1.220 & 0.761 & 1.290 & 0.793 & 0.145 & 0.866 & 0.154 \\
\hline 12.5 & 0.741 & 1.060 & 0.798 & 1.104 & 0.830 & 1.168 & 0.864 & 1.231 & 0.944 & 1.311 \\
\hline 25 & 0.817 & 0.944 & 0.881 & 0.984 & 0.916 & 1.041 & 0.954 & 1.097 & 1.041 & 1.168 \\
\hline
\end{tabular}

By combining Eqs. (1), (3), and (4), different $U_{e}$ for each of the five ambient pressures are obtained, which are $172.20 \mathrm{~m} / \mathrm{s}, 164.54 \mathrm{~m} / \mathrm{s}, 156.52 \mathrm{~m} / \mathrm{s}, 148.05$ $\mathrm{m} / \mathrm{s}$, and $139.06 \mathrm{~m} / \mathrm{s}$, respectively.

For the viscous sublayer thickness, $\delta_{1}$, it can be obtained by [24]:

$$
\delta_{l}=\frac{32.8 d}{\operatorname{Re} \sqrt{\lambda}} .
$$

And $R e$ is expressed by:

$$
\operatorname{Re}=\frac{u d}{v}
$$

where $v$ is the fluid kinematic viscosity coefficient.

In terms of $\lambda$, it depends on Re and can be calculated as follows [24]:

$$
\begin{aligned}
& \text { For } 10^{4}<\operatorname{Re}<26.98\left(\frac{d}{\Delta}\right)^{8 / 7} \text { : } \\
& \frac{1}{\sqrt{\lambda}}=2 \lg (\operatorname{Re} \sqrt{\lambda})-0.8,
\end{aligned}
$$

where $\Delta$ is the absolute surface roughness, here, it is the surface roughness value.

$$
\begin{gathered}
\text { For } 26.98\left(\frac{d}{\Delta}\right)^{8 / 7}<\operatorname{Re}<4160\left(\frac{d}{2 \Delta}\right)^{0.85}: \\
\frac{1}{\sqrt{\lambda}}=-2 \lg \left(\frac{\Delta}{3.7 d}+\frac{2.51}{\operatorname{Re} \sqrt{\lambda}}\right) .
\end{gathered}
$$

For $\operatorname{Re}>4160\left(\frac{d}{2 \Delta}\right)^{0.85}$ :

$$
\frac{1}{\sqrt{\lambda}}=1.74+2 \lg \frac{d}{2 \Delta} \text {. }
$$

From Eqs. (5) to (9), $\delta_{1}$ at each roughness value and each ambient pressure can be achieved, shown in Table 3 .
Moreover, the important parameter defining cavitation intensity is cavitation number, $\sigma$, which can be expressed as:

$$
\sigma=\frac{P_{a}-P_{v}}{\left(\rho U_{e}^{2}\right) / 2},
$$

where $P_{v}$ is the vapor pressure of the liquid.

From Table 3, it can be observed that the viscous sublayer thickness not only depends on the ambient pressure but also largely depends on the roughness value. And the sublayer thicknesses at chamber and exit are much different, particularly when the surface is relatively smooth, say $0.8 \mu \mathrm{m}$ and $1.6 \mu \mathrm{m}$. The data also looks irregular. However, from the optimal surface roughness in Fig. 6, it seems that the viscous sublayer thicknesses at chamber and exit determine the erosion intensity respectively, depending on the surface roughness value. For example, at roughness values of $0.8 \mu \mathrm{m}$ and $1.6 \mu \mathrm{m}$, the viscous sublayer thickness is around $10 \mu \mathrm{m}$, which is much thicker than the roughness element. As a result, the roughness elements are totally covered by the viscous sublayer and can hardly influence the turbulence core. Thus, the cavitation erosion intensities are similar.

When the viscous sublayer thickness at nozzle exit changes abruptly, the corresponding surface roughness results in the strongest cavitation erosion intensity. However, this is not applicable to the case of roughness value of $6.3 \mu \mathrm{m}$ and ambient pressure of $6 \mathrm{MPa}$. Under this case, a roughness value of $6.3 \mu \mathrm{m}$ is the one that causes the abrupt change, but roughness value of $12.5 \mu \mathrm{m}$ is the optimum. Even with this inconsistency, the curves of roughness values of $6.3 \mu \mathrm{m}$ and $12.5 \mu \mathrm{m}$ nearly experience the same tendency. However, due to the rather limited literature on the effects of nozzle inner surface roughness, it is currently very difficult to provide an explanation for this phenomenon. Further theoretical and mathematical investigations need to be performed. 
It is also observed in the figure that at an ambient pressure of $4 \mathrm{MPa}$, each surface roughness can cause a greater mass loss around the optimum standoff distance compared to those under the other ambient pressures, meaning a certain degree of ambient pressure can enhance the cavitation erosion intensity of SRCW. The fact that the jet has the strongest cavitation erosion intensity at an ambient pressure around $5 \mathrm{MPa}$ is in good agreement with the results obtained by Johnson et al. [11], demonstrating the reliability of our research.

\section{CONCLUSIONS}

For the purpose of enhancing the cavitation intensity of SRCW under ambient pressures, the effects of nozzle inner surface roughness values were studied by means of erosion testing. Unfortunately, there is currently little literature on the effects of nozzle inner surface roughness. Further investigations need to be conducted to understand the interactions of surface roughness and cavitation. However, the present study brings light to some evidence:

1. Under the experimental conditions, nozzle inner surface roughness has dramatic effects on the cavitation erosion performance of SRCW, which seems to largely depend on the viscous sublayer thickness. Corresponding to each ambient pressure, an optimum roughness value for achieving the strongest cavitation intensity exists.

2. The optimal surface roughness almost occurs at the place where the viscous sublayer thickness at the nozzle exit changes abruptly.

3. The existence of an optimum standoff distance is a common feature of SRCW, and the surface roughness affects its exact value of the optimum standoff distance.

4. A certain ambient pressure enhances cavitation erosion intensity, which is another feature of SRCW regardless of nozzle inner surface roughness.

\section{ACKNOWLEDGEMENTS}

This research is financially supported by the National Key Basic Research Program of China (No. 2014CB239203), the National Natural Science Foundation of China (No. 51474158) and the China Scholarship Council (No. 201406270047).

\section{REFERENCES}

[1] Karadžič, U., Bulatović, V., Bergant, A. (2014). Valve-induced water hammer and column separation in a pipeline apparatus. Strojniški vestnik - Journal of Mechanical Engineering, vol. 60, no. 11, p. 742-754, D0l:10.5545/sv-jme.2014.1882.

[2] Kim, K.H., Chahine, G., Franc, J.P., Karimi, A. (eds.) (2014). Advanced Experimental and Numerical Techniques for Cavitation Erosion Prediction. Springer, Dordrecht, DOI:10.1007/978-94-017-8539-6.

[3] Ciubotariu, C.R., Secosan, E., Marginean, G., Frunzaverde, D., Campian, V.C. (2016). Experimental study regarding the cavitation and corrosion resistance of Stellite 6 and self-fluxing remelted coatings. Strojniški vestnik - Journal of Mechanical Engineering, vol. 62, no. 3, p. 154-162, D0l:10.5545/svjme.2015.2663.

[4] Heath, D., Širok, B., Hočevar, M., Pečnik, B. (2013). The use of the cavitation effect in the mitigation of $\mathrm{CaCO} 3$ deposits. Strojniški vestnik - Journal of Mechanical Engineering, vol. 59, no. 4, p. 203-215, D0l:10.5545/sv-jme.2012.732.

[5] Perec, A., Pude, F., Stirnimann, J., Wegener, K. (2015). Feasibility study on the use of fractal analysis for evaluating the surface quality generated by waterjet. Tehnički vjesnik Technical Gazette, vol. 22, no. 4, p. 879-883, D0l:10.17559/ TV-20140128231244.

[6] Chahine, G.L., Kapahi, A., Choi, J.K., Hsiao, C.T. (2016). Modeling of surface cleaning by cavitation bubble dynamics and collapse. Ultrasonics Sonochemistry, vol. 29, p. 528-549, D0I:10.1016/j.ultsonch.2015.04.026.

[7] Dalfré Filho, J.G., Assis, M.P., Genovez, A.I.B. (2015). Bacterial inactivation in artificially and naturally contaminated water using a cavitating jet apparatus. Journal of Hydro-environment Research, vol. 9, no. 2, p. 259-267, D0l:10.1016/j. jher.2015.03.001.

[8] Biluš, I., Bombek, G., Hočevar, M., Širok, B., Cenčič, T., Petkovšek, M. (2014). The experimental analysis of cavitating structure fluctuations and pressure pulsations in the cavitation station. Strojniški vestnik - Journal of Mechanical Engineering, vol. 60, no. 3, p. 147-157, D0l:10.5545/svjme.2013.1462.

[9] Soyama, H. (2013). Effect of nozzle geometry on a standard cavitation erosion test using a cavitating jet. Wear, vol. 297, no. 1-2, p. 895-902, D0I:10.1016/j.wear.2012.11.008.

[10] Zhou, J., Hu, J. Jing, C. (2016). Lumped parameter modelling of cavitating orifice flow in hydraulic systems. Strojniški vestnik Journal of Mechanical Engineering, vol. 62, no. 6, p. 373-380, DOI:10.5545/sv-jme.2015.3082.

[11] Johnson, V.E. Jr., Lindenmuth, W.T., Conn, A.F., Frederick, G.S. (1981). Feasibility study of tuned-resonator, pulsating cavitating water jet for deep-hole drilling. (No. SAND-81-7126). Sandia National Labs., Albuquerque, Hydronautics, Inc., Laurel., D0I:10.2172/6266875.

[12] Li, D., Kang, Y., Ding, X., Wang, X., Fang, Z. (2016). Effects of area discontinuity at nozzle inlet on the characteristics of selfresonating cavitating waterjet. Chinese Journal of Mechanical Engineering, vol. 29, no. 4, p. 813-824, D0l:10.3901/ CJME.2016.0426.060. 
[13] Johnson, V.E. Jr, Chahine, G.L., Lindenmuth, W.T., Conn, A.F., Frederick, G.S., Giacchino, G.J. (1984). Cavitating and structured jets for mechanical bits to increase drilling rate-Part I: Theory and concepts. Journal of Energy Resources Technology, vol. 106, no. 2, p. 282-288, DOI:10.1115/1.3231053.

[14] Chahine, G.L., Johnson, V.E. (1985). Mechanics and applications of self-resonating cavitating jets. International Symposium on Jets and Cavities, ASME, WAM, p. 21-33.

[15] Li, D., Kang, Y., Ding, X., Wang, X. Fang, Z., (2016). Effects of area discontinuity at nozzle inlet on the characteristics of high speed self-excited oscillation pulsed waterjets. Experimental Thermal and Fluid Science, vol. 79, p. 254-265, Dol:10.1016/j.expthermflusci.2016.07.013.

[16] Li, Z. (2014). Criteria for jet cavitation and cavitation jet drilling. International Journal of Rock Mechanics and Mining Sciences, vol. 71, p. 204-207, D0l:10.1016/j.jijmms.2014.03.021.

[17] Johnson, V.E. Jr, Chahine, G.L., Lindenmuth, W.T., Conn, A.F., Frederick, G.S., Giacchino, G.J. (1984). Cavitating and structured jets for mechanical bits to increase drilling rate-Part II: Experimental results. Journal of Energy Resources Technology, vol. 106, no. 2, p. 289-294, Dol:10.1115/1.3231054.

[18] Li, G., Shi, H., Liao, H., Shen, Z., Niu, J., Huang, Z., Luo, H. (2009). Hydraulic pulsed cavitating jet-assisted drilling. Petroleum Science and Technology, vol. 27, no. 2, p. 197-207, DOI:10.1080/10916460701700302.

[19] Echouchene, F., Belmabrouk, H., Le Penven, L., Buffat, M. (2011). Numerical simulation of wall roughness effects in cavitating flow. International Journal of Heat and Fluid Flow, vol. 32, no. 5, p. 1068-1075, D0l:10.1016/j. ijheatfluidflow.2011.05.010.

[20] Chang, J.C., Huang, S.B. Lin, C.M. (2006). Effects of inlet surface roughness, texture, and nozzle material on cavitation. Atomization and Sprays, vol. 16, no. 3, p. 299-318, D0I:10.1615/AtomizSpr.v16.i3.40.

[21] [21] Li, D., Li X., Kang, Y, Wang, X., Long, X., Wu, S. (2015). Experimental investigation on the influence of internal surface roughness of organ-pipe nozzle on the characteristics of high speed jet. Journal of Mechanical Engineering, vol. 51, no. 17, p. 169-176, D0l:10.3901/JME.2015.17.169. (in Chinese)

[22] Li, D., Kang, Y., Wang, X., Ding, X., Fang, Z. (2016). Effect of nozzle inner surface roughness on the cavitation erosion characteristics of high speed submerged jets. Experimental Thermal and Fluid Science, vol. 74, p. 444-452, D0I:10.1016/j. expthermflusci.2016.01.009.

[23] Schubauer, G.B. Tchen, C.M., (2015). Turbulent Flow. Princeton University Press, Princeton.

[24] Elger, D.F., Roberson, J.A. (2013). Engineering Fluid Mechanics. Wiley, New York.

[25] Nikuradse, J. (1950). Laws of Flow in Rough Pipes. National Advisory Committee for Aeronautics, Washington.

[26] Li, X., Meng, J., Li, Z. (2011). Roughness enhanced mechanism for turbulent convective heat transfer. International Journal of Heat and Mass Transfer, vol. 54, no. 9, p. 1775-1781, DOI:10.1016/j.jijheatmasstransfer.2010.12.039.

[27] Li, D., Kang, Y., Ding, X., Wang, X., Fang, Z. (2016). An experimental investigation on the pressure characteristics of high speed self-resonating pulsed waterjets influenced by feeding pipe diameter. Journal of Mechanical Science and Technology, vol. 30, no. 11, p. 4997-5007, D0l:10.1007/ s12206-016-1019-3.

[28] Hattori, S., Goto, Y., Fukuyama, T. (2006). Influence of temperature on erosion by a cavitating liquid jet. Wear, vol. 260, no. 11-12, p. 1217-1223, D0l:10.1016/j. wear.2005.08.001.

[29] Momma, T., Lichtarowicz, A. (1995). A study of pressures and erosion produced by collapsing cavitation. Wear, vol. 186-187, p. 425-436, DOI:10.1016/0043-1648(95)07144-X.

[30] Soyama, H. (2011). Enhancing the aggressive intensity of a cavitating jet by means of the nozzle outlet geometry. Journal of Fluids Engineering, vol. 133, no. 10, no. 101301, DOl:10.1115/1.4004905.

[31] Li, G., Shen, Z., Zhou, C., Zhang, D., Chen, H. (2005). Investigation and application of self-resonating cavitating water jet in petroleum engineering. Petroleum Science and Technology, vol. 23, no. 1, p. 1-15, D0I:10.1081/LF20009686218.

[32] Kerst, A.W., Judat, B., Schlünder, E.-U. (2000). Flow regimes of free jets and falling films at high ambient pressure. Chemical Engineering Science, vol. 55, no. 19, p. 4189-4208, DOI:10.1016/S0009-2509(00)00074-9.

[33] Numachi, F., Ōba, R., Chida, I. (1965). Effect of surface roughness on cavitation performance of hydrofoils-Report 1. Journal of Basic Engineering, vol. 87, no. 2, p. 495-502, DOI:10.1115/1.3650583. 